Área Abierta. Revista de comunicación

audiovisual y publicitaria

ISSN: 2530-7592 / ISSNe: 1578-8393

\title{
Escribir con luz la mirada. Expresiones y metadiscursos de la fotografía- documento en el contexto contemporáneo español
}

\author{
Marta Martín Núñez
}

Recibido: 9 de abril de 2020 / Aceptado: 4 de junio de 2020

Resumen. El presente artículo explora el uso de la luz en la fotografía no como un proceso técnico necesario, sino como un potente generador discursivo que escribe una mirada, un punto de vista sobre el mundo, al tiempo que reflexiona sobre el propio proceso. Confrontando las lógicas y los usos de la fotografía en distintos momentos históricos, podremos entender cómo ha ido cambiando la concepción de la luz bajo diferentes sensibilidades artísticas, que nos ayudarán a enmarcar tres proyectos contemporáneos a los que queremos prestar especial atención: Sputtering, de Jorge Isla (2017); Sol, de Ricardo Cases (2017) y C.E.N.S.U.R.A de Julián Barón (2011). Estos proyectos nos permitirán aproximarnos a tres fuentes de luz -fluorescente, solar y flash-y a tres formas de deconstruirla. En los tres proyectos la luz trasciende su mera función como posibilitadora de la imagen para enunciar la mirada autoral y metadiscursiva en el marco de la fotografía contemporánea española.

Palabras clave: Fotografía española; Luz; Flash; Julián Barón; Ricardo Cases; Jorge Isla

\section{[en] To Write a View with Light. Expressions and Metadiscourses of the Photography-Document in the Contemporary Spanish Context}

\begin{abstract}
This article explores the use of light in photography not as a necessary technical process, but as a powerful discursive generator that writes a point of view about the world, while it reflects on its own process. Confronting the logics and uses of photography in different historical moments, we can understand how the conception of light has changed under different artistic sensibilities, which will help us to frame three contemporary projects to which we want to pay special attention: Sputtering, by Jorge Isla (2017); Sol, by Ricardo Cases (2017) and C.E.N.S.U.R.A by Julián Barón (2011). These projects will allow us to approach three light sources -fluorescent, solar and flash-and three ways of deconstructing it. Results will show how the three projects use light beyond its role as a mere image enabler to articulate the author's view while building a metadiscourse within the framework of contemporary Spanish photography.
\end{abstract}

Keywords: Spanish photography; Light; Flash; Julián Barón; Ricardo Cases; Jorge Isla

Sumario. 1. Introducción y aproximación metodológica. La luz, registro y expresión. 2. La luz y el hecho fotográfico: entre el documento y el arte. 3. La luz en la fotografía contemporánea: la hibridación de la fotografía-documento y los procesos artísticos. 4. La luz que escribe la mirada. Análisis de casos. 5. Discusión y conclusiones. 6. Financiación. 7. Uso de imágenes. 8. Bibliografía.

Cómo citar. Martín Núñez, Marta (2020). Escribir con luz la mirada. Expresiones y metadiscursos de la fotografía-documento en el contexto contemporáneo español. Área Abierta. Revista de comunicación audiovisual y publicitaria 20 (2), 251-267, http://dx.doi.org/10.5209/arab.68725

Universitat Jaume I (España)

E-mail:mnunez@uji.es 


\section{Introducción. Un código, una moral}

La luz y la sombra. La luz produce la sombra. Un contraste complementario. La luz total vuelve invisible. ¿Escribir con luz? La luz quema la capa sensible, es el negro. Al revelar en papel la impresión, invertimos el efecto. Contradicción concordante. Solo hacemos que la imagen se vuelva negra. La melanografía. [...] Las sombras ya no hablan de la significación, solo dan la imagen de una cosa, que no sigue siendo cosa, que evoca otra cosa que la cosa [...] Es la desintegración por la luz, que no habla más que por las luces, que cambia la cosa en una imagen de-significativa. Es por la melanografía que me entero del carácter secreto de los signos que no significan más que lo que la cosa pretende significar (Raoul Hausmann, en Chéroux, 2009: 93) ${ }^{2}$.

Aunque etimológicamente la fotografía es la escritura de la luz, Raoul Hausmann, a través de sus melanografías ya nos señala que la luz y la oscuridad son dos caras de la misma moneda. Incluso Barthes nos recuerda que atiende a más matices. "Parece ser que en latín 'fotografía' se diría: imago lucís opera expressa; es decir: imagen revelada, 'salida', 'elevada', 'exprimida' -como el zumo de un limón- por la acción de la luz” (Barthes, 1989: 127). La luz revela, hace salir, eleva o exprime la imagen. Es un proceso físico, en un primer momento y químico -o ya electrónico-, en un segundo momento, el que permite la existencia de la fotografía. La luz es energía radiante que viaja en fotones y que interactúa con el material al que impacta. Los materiales fotosensibles reaccionan a la luz y la inscriben en la película, en el sensor, que después es procesado en la oscuridad para hacer emerger la imagen latente. La luz -y las sombras-son, por tanto, parte del proceso técnico esencial del proceso de registro fotográfico que genera la expresión de su lenguaje. Su relevancia se deja notar en la importancia que se concede desde las instituciones fotográficas al aprendizaje y control de su proceso y funcionamiento, -casi- siempre desde este punto de vista.

Sin embargo, aquí no nos interesa esta aproximación técnica, que responde a la capacidad de la fotografía de representar el mundo visible, de registrar y de erigirse como una huella de lo real, lo que André Rouillé ha llamado la imagen-documento, y la base a partir de la cual se ha construido gran parte de la teoría e historia fotográfica, convirtiéndose también en el rasgo por excelencia de la fotografía que después es re-mediado en otros medios (Martín-Núñez, 2009, 2011). Aquí nos interesa su capacidad discursiva y metadiscursiva, de la fotografía-expresión: cómo la expresión de la luz, más allá de registrar, es capaz de construir mundos, en palabras de Rouillé: "Mientras que la huella va de la cosa -preexistente a la imagen-, lo que importa es

Raoul Hausmann, citado por Michel Giroud. Raoul Hausmann Je ne suis pas photographe, París, Chene, 1975, pp. 72-77. En 1969, Raoul Hausmann le cambió el nombre por Mélanographie -nombre de una recopilación epónima: Mélanographie, París, Sic, 1969- a tres fotografías, tomadas en 1931 en Checoslovaquia, y llamadas anteriormente Ombres I,II y III. 
explorar cómo la imagen produce lo real" (2017: 27). La hipótesis que arranca este trabajo, por tanto, es explorar los mecanismos expresivos de una fotografía que, pese a mantener vínculos con la esencia de la concepción de la fotografía-documento, abraza la expresión y la reivindicación de la mirada autoral para escribir un punto de vista sobre el mundo. Y, en este camino, reflexiona sobre su propia función: la luz que alumbra, que transforma y que ciega. La luz se convierte así no solo en el principal elemento de registro, también en el elemento expresivo que lo posibilita y en un elemento metadiscursivo.

A lo largo de las próximas páginas exploraremos el lugar que ha ocupado la luz como elemento fotográfico en tensión entre la concepción de documento y arte para contextualizar el análisis de los tres proyectos que nos permitirán explorar las ideas que hemos apuntado. Se trata de un corpus de casos de estudio paradigmáticos que nos permiten profundizar en el uso de la luz desde la investigación sobre tres fuentes distintas: Sputtering, de Jorge Isla (2017), reflexiona sobre la realidad que vemos a partir de la descomposición física de la luz fluorescente; Sol, de Ricardo Cases (2017), explora la incidencia del sol en el territorio; y C.E.N.S.U.R.A. de Julián Barón (2011) que quema la imagen con flashazos para denunciar la ceguera ante la corrupción política. Los tres proyectos giran en torno a los efectos de la propia luz como tema central, además de ser el principal elemento de expresión para generar el discurso que enuncian. Pero, además, los tres proyectos mantienen vínculos con la concepción de la fotografía-documento, superando su estética normativa para hacerla relevante en su discurso. De este modo, utilizan la materialidad de la fotografía, su elemento principal, para generar su discurso, evitando la transparencia en la enunciación y la inmediatez ante el lector.

Para aproximarnos a estos proyectos, adoptaremos una perspectiva semiótica para su análisis que nos permita abordar la imagen como un texto en el que el significado emerge de su propia materialidad. Siguiendo la metodología de la imagen fotográfica propuesta por Javier Marzal (2007: 171-3), partimos de la necesidad de entender el texto fotográfico como una práctica significante donde los detalles contextuales se combinan con el análisis de los elementos morfológicos, compositivos y enunciativos. Este modelo parte de la consideración de la forma y del contenido como niveles profundamente imbricados y comprometidos en los que la enunciación queda escrita en la propia materialidad de la imagen. La metodología propuesta contempla cuatro niveles que detallamos en la tabla uno, con diferentes ítems de análisis que hemos aplicado al conjunto de las imágenes de los proyectos analizados, a la que le sumamos un quinto nivel que contempla también el análisis de la estructura del relato y el soporte que la alberga como elementos significantes.

\begin{tabular}{|l|l|}
\hline Nivel & Ítems analizados \\
\hline \multirow{4}{*}{ I. Nivel contextual } & $\begin{array}{l}\text { 1. Datos generales (título, autor, nacionalidad, año, procedencia, } \\
\text { género, movimiento) }\end{array}$ \\
\cline { 2 - 2 } & $\begin{array}{l}\text { 2. Parámetros técnicos (BN/color, formato, cámara, soporte, ob- } \\
\text { jetivo, otros) }\end{array}$ \\
\cline { 2 - 2 } & $\begin{array}{l}\text { 3. Datos biográficos y críticos (hechos biográficos relevantes, co- } \\
\text { mentarios críticos sobre el autor) }\end{array}$ \\
\hline
\end{tabular}




\begin{tabular}{|c|c|}
\hline II. Nivel morfológico & $\begin{array}{l}\text { 1. Elementos morfológicos (punto, línea, plano/espacio, escala, } \\
\text { forma, textura, nitidez, iluminación, contraste, color, otros) }\end{array}$ \\
\hline \multirow{3}{*}{ III. Nivel compositivo } & $\begin{array}{l}\text { 1. Sistema sintáctico o compositivo (perspectiva, ritmo, tensión, } \\
\text { proporción, distribución de pesos, ley de tercios, orden icónico, } \\
\text { recorrido visual, estaticidad, dinamicidad, pose) }\end{array}$ \\
\hline & $\begin{array}{l}\text { 2. Espacio de la representación (campo/fuera de campo, abierto/ } \\
\text { cerrado, interior/exterior, concreto/abstracto, profundo/plano, ha- } \\
\text { bitabilidad, puesta en escena, otros) }\end{array}$ \\
\hline & $\begin{array}{l}\text { 3. Tiempo de la representación (instantaneidad, duración, atem- } \\
\text { poralidad, tiempo simbólico, tiempo subjetivo, secuencialidad/ } \\
\text { narratividad, otros) }\end{array}$ \\
\hline IV. Nivel enunciativo & $\begin{array}{l}\text { 1. Articulación del punto de vista (Puntos de vista físico, actitud de } \\
\text { los personajes, calificadores, transparencia, sutura, verosimilitud, } \\
\text { marcas textuales, miradas de los personajes, enunciación, relacio- } \\
\text { nes intertextuales, otros) }\end{array}$ \\
\hline \multirow{4}{*}{$\begin{array}{l}\text { V. Elementos cons- } \\
\text { tructivos del relato }\end{array}$} & $\begin{array}{l}\text { 1. Diseño espacial de la serie (relaciones espaciales y compositi- } \\
\text { vas entre las fotografías) }\end{array}$ \\
\hline & $\begin{array}{l}\text { 2. Diseño temporal de la serie (relaciones temporales entre las fo- } \\
\text { tografías) }\end{array}$ \\
\hline & $\begin{array}{l}\text { 3. Diseño estructural de la serie (construcción estructural del re- } \\
\text { lato) }\end{array}$ \\
\hline & $\begin{array}{l}\text { 4. Diseño del soporte (elementos de diseño del fotolibro o diseño } \\
\text { expositivo) }\end{array}$ \\
\hline
\end{tabular}

Tabla 1. Adaptación de la metodología de la imagen fotográfica [Fuente: Javier Marzal, 2007. Transcripción]

\section{La luz y el hecho fotográfico: entre el documento y el arte}

Para Raich Muñoz, "la primera mirada no es la de ningún creador; la primera mirada fotográfica sobre la realidad perteneció solo a la propia luz" (2014: 20). Efectivamente, la fotografía nace vinculada al registro de la huella de la luz. Pero cuando Niépce consigue fijar en 1827 su Vista desde la ventana en Le Gras, no solo consigue que la luz se inscriba y registre la imagen tomada en la ventana de su estudio, también da cuenta de cómo el paso del tiempo se inscribe en el espacio durante el lapso de un obturador abierto en un dispositivo articulado por su mirada. Aunque con pretensiones puramente funcionales, científicas, deja inscrito en un encuadre el recorrido del sol (del planeta, más bien) sobre la finca de Le Gras. La obsesión de los primeros tiempos se centrará en obtener una imagen mecánica, objetiva, legible, figurativa, acorde con el imperativo ideológico del momento y la necesidad que la fotografía viene a satisfacer. Fontcuberta lo explica del siguiente modo:

Lo que conocemos comúnmente como fotografía solo cristaliza a principios del siglo XIX porque es justamente en ese momento cuando la cultura tecnocientífica del positivismo requerirá un procedimiento que certifique la observación empírica 
de la naturaleza. La cámara aparece, pues, ligada a las nociones de objetividad, de verdad, de identidad, de memoria, de documento, de archivo (2010: 61).

Así, la cámara fotográfica nace vinculada a un uso científico que cree ser objetivo, al prometer liberar la imagen de la mano del artista -aunque esto no signifique que lo libera también de su mirada-. Como indica Rouillé, la fotografía ha quedado reducida muchas veces al funcionamiento elemental de su dispositivo, a su más simple expresión de huella luminosa, de índice, de mecanismos de registro. Así, el paradigma de la fotografía es construido a partir de su grado cero, de su principio técnico, asimilado frecuentemente a un mero automatismo (2017: 26). La fotografía en el siglo XIX viene a responder a las necesidades de esta sociedad, "lo que la proyectó al corazón de la modernidad y le permitió acceder al papel de documento, es decir, a poder equivaler legítimamente a las cosas que figuraba" (2017: 43). Esta actitud inicial, que establece lo normativo y privilegia un tipo de fotografía anclada al referente, transparente, influirá notablemente en la construcción de una tradición documental y fotoperiodística de la fotografía, de la cual los fotógrafos de la Farm Security Adminsitration se consideran una referencia, y que marcan la dirección hegemónica de la fotografía que quedará inscrita en los genes del propio medio, vinculada además a las nociones de realidad y veracidad que, pese a las falacias que encierran, han acompañado al medio durante buena parte de su historia, como ha argumentado Fontcuberta tanto en sus escritos -1997, 2010, 2016- como en su propia obra.

Las pretensiones de la fotografía como medio artístico llegarían un poco más tarde, de la mano de la élite aristocrática en una necesidad de diferenciarse del uso masivo que se hacía de la fotografía hacia finales del XIX. Pero el Pictorialismo, y después la Fotografía Directa y los movimientos de vanguardia europeos trabajarían la expresividad de la luz desde postulados antagónicos. El Pictorialismo trabajará desde la acentuación de la luz en combinación con imágenes borrosas o el sacrificio de los detalles, de la mano de artistas como Margaret Cameron o Robert Damachy, cuyas prácticas no siempre fueron aceptadas sin críticas (Poivert, 2009: 200). Manipulando la superficie de la imagen (Gunther y Poivert, 2009: 604) estaban comprometidos con el reconocimiento del estatus artístico de la fotografía a partir de la reproducción imperfecta de la realidad, pero al modo de la disciplina artística de referencia, la pintura. La Fotografía Directa, que llegará desde Estados Unidos para contestar al Pictorialismo, reivindicará un arte puramente fotográfico, rechazando cualquier manipulación y explorando las características propias del medio: inmediatez, precisión, y exaltación de las formas puras a través del uso técnico de la luz. En este contexto, serán los fotógrafos del Grupo f/64 quienes desarrollarán después estos postulados, especialmente Ansel Adams gracias a su Sistema de Zonas -un proceso para calcular la luz correcta en cada ocasión (Langford, 2008: 420)- cuyos paisajes son un alegato a una exposición técnicamente perfecta.

Sin embargo, serán los movimientos de vanguardia europeos los que más nos interesan aquí: trabajarán con la fotografía por su condición de documento moderno, al tiempo que la someten a procesos experimentales para su expresión, abrazando esta cualidad aparentemente contradictoria del medio fotográfico. Las sombras, la experimentación y el error se convierten en fuente de creación. El cuestionamiento de la mímesis en el siglo XX constituye una de las puntas de lanza de las vanguardias, cuando no su caballo de batalla preferido (Chéroux, 2009: 190). El error, 
precisamente en fotografía, corresponde a una alteración del poder mimético de la imagen: cuanto más defectuosa resulta, menos se asemeja a la realidad (Chéroux, 2009; 188); era considerado como algo contra-natura o no-productivo y, por tanto, excluido. En este sentido, tanto la obra de Moholy-Nagy como de Man Ray, desde perspectivas diferentes, nos muestran nuevos lugares de exploración de la luz y la imagen fotográfica, totalmente contrarias a la sistematización de Adams. A través de la exploración de las sombras, especialmente la suya como autor, Moholy-Nagy enfatizó la idea de un autor presente -que se representa-y una técnica que se celebra, lejos de la transparencia y la creencia de la fotografía como mirada objetiva en su trabajo con los fotogramas. Man Ray se interesó por los destellos y los reflejos, reivindicando en este caso el azar. Como reconoció Bretón, los surrealistas enseguida se sintieron atraídos por lo accidental, la coincidencia o la sorpresa. En la fotografía estos accidentes se traducían en modificaciones inesperadas del tema, pero también la solarización, las manchas, las imágenes fuera de foco y, por supuesto, los reflejos. Como indica Boulouch, "la rayografía transforma los objetos familiares, usuales, hasta hacer que pierdan sus propiedades iniciales" creando representaciones misteriosas y efímeras en las que lo que les interesa a los surrealistas es el encuentro fortuito y efímero de un objeto y un rayo luminoso sobre un papel sensible que encarnan una forma instantánea de escritura automática (2009: 469).

\section{La luz en la fotografía contemporánea: la hibridación de la fotografía- documento y los procesos artísticos}

Pese al decaimiento de los movimientos de vanguardia en la segunda mitad del siglo XX, muchas de sus concepciones y prácticas siguen resonando en la fotografía contemporánea. Su compleja articulación entre documento y arte, modulada por las distintas necesidades y sensibilidades de diferentes épocas, nos traen hasta una fotografía que nos da muestras de una hibridación entre la fotografía con carácter de documento con las más diversas prácticas artísticas, donde no siempre se privilegia la lecturabilidad de las imágenes, sino la expresión subjetiva, el juego y la experimentación con ellas, proponiendo retos y lecturas más pausadas -y profundas- a los espectadores y que ha permitido miradas desde una dimensión híbrida, como señala el estudio sobre la fotografía documental en la obra de mujeres artistas (Clemente-Fernández et al, 2018). El fotógrafo Paul Graham, una de las figuras contemporáneas que mejor ha entendido esta hibridación, destaca que "la fotografía es un medio con un vínculo único y particular con la realidad", ya que "la antigua conciencia" era observar la realidad y poner la cámara frente al mundo. "El problema es que en las dos últimas décadas nuestra percepción de la realidad ha cambiado de algo 'allá afuera' a algo 'dentro de nosotros'", y esta 'nueva conciencia' ha sido dura con la fotografía, debido a su adicción al mundo observable (Grosenick, 1995). De hecho, el trabajo de Graham en los últimos treinta años ha sido marcadamente metafórico, donde el sujeto aparente o superficial representa e ilustra al mismo tiempo uno más profundo. Como sentencia Josep Maria Català: "se crea lo que se crea o se haga lo que se haga, la nueva realidad hay que pensarla, gestionarla y conducirla desde la imaginación" (2012: 42).

En el contexto español, no podemos obviar la fotografía de Carlos Pérez Siquer, cofundador junto a José María Artero del grupo AFAL, que generará una pequeña 
revolución en el panorama de la fotografía española de los años cincuenta y sesenta. Su mirada a la playa, que se extiende desde los años setenta a los años noventa, desde el color y la luz, incorporando algunas abstracciones formales e ironías de la sociedad de consumo, adelantarán algunas de las ideas que después han trabajado con maestría fotógrafos como Martin Parr, y que podemos encontrar también en el trabajo de Ricardo Cases. Pérez Siquer, además, más recientemente, ha realizado estudios sobre la sombra -su sombra, profundizando más en las dicotomías que establece la luz y la autorrepresentación. La obra de Paul Graham también nos permite comprender esta tensión entre documento y arte. Proyectos como American Night (2011) muestran, a partir del error de laboratorio y la accidental sobreexposición de la imagen, una reflexión sobre la ceguera en la sociedad americana frente a la pobreza, en un juego perverso de sobreexposiciones, subexposiciones y saturaciones. Este gesto será el que, como veremos, Barón se lleve al campo de la política para reflexionar sobre la ceguera de los propios medios de comunicación y la visibilidad que dan a ciertos temas, generando un ruido que Barón borra de la imagen con sus flashazos.

Por otra parte, la experimentación con la materialidad fotografía ha sido constante desde su nacimiento y continúa siendo una fuente para la creación. La Tate Modern de Londres organizaba en 2018 la primera gran exposición sobre la experimentación a través de la luz desde 1910 hasta la fotografía contemporánea analizando relaciones entre la fotografía y la pintura abstracta, incluyendo la obra de los pioneros, a los que hemos mencionado antes, pero también la de artistas contemporáneos que siguen trabajando con fotogramas. Resulta destacable el trabajo de Barbara Kasten -su proyecto Amalgam de 1979 supuso su iniciación en su carrera fotográfica, trabajando en la creación de sombras complejas a partir del trabajo con la luz en el fotograma- o de Thomas Ruff - cuyos trabajos con fotogramas los traslada a un cuarto oscuro digital que le permite ajustar totalmente todas las condiciones lumínicas. En la exposición también se incluía muestras de trabajos de fotógrafos de una nueva generación, como Antony Cairns, Maya Rochat o Daisuke Yokota que trabajan a partir de los procesos experimentales con la luz y la materia.

En este sentido, el propio Paul Graham publicaba en 2011 Films, que recoge sus treinta últimos años de trabajo. Se trata de una mirada amplificada a los negativos no expuestos de sus carretes, que nos muestra una mirada retrospectiva y negativa a la superficie que la luz no consiguió impresionar en sus trabajos. Esta mirada al grano fotográfico es, al mismo tiempo, un tributo estético al medio y un registro científico, como nos muestra Isla en su investigación sobre la luz. Y nos resulta especialmente interesante el trabajo de Wolfgang Tillmans que ha estado, desde sus inicios como fotógrafo en los noventa, interesado en guardar los errores ocurridos en el cuarto oscuro, tomándolos como accidentes interesantes sobre los que trabajar. Más allá de sus trabajos donde buscaba la abstracción a partir de sobredimensionar imágenes con una fotocopiadora, su serie Blushes y Super Colliders consisten en la experimentación con diferentes fuentes de luz, en los que busca sintonizar con los propios materiales que utiliza en su fotografía, con los tiempos y movimientos para generar imágenes que transforman estos gestos y energías.

La luz es, pues, materia prima de creación, y también de expresión, colocándose muchas veces en el centro de la tensión existente entre la concepción de la fotografía como documento y como arte a través de su materia. En los análisis que siguen, exploraremos esta vinculación de la fotografía con el documento y su relación con 
las prácticas artísticas a partir del uso que los autores hacen de la luz como principio de creación y expresión. Sin embargo, lo que nos interesa de ellos es una lectura metadiscursiva, ya que, a través de la investigación y la experimentación con la luz, no solo lanzan una lectura sobre el mundo, también sobre la propia concepción de la fotografía.

\section{La luz que escribe la mirada. Análisis de casos}

\subsection{Revelar lo que no vemos. Sputtering de Jorge Isla (2017)}

Sputtering es un proyecto que hace visible, a partir del mecanismo del obturador, aquello de la luz fluorescente que no es visible al ojo humano. Desde el propio título del proyecto, Jorge Isla ya nos ofrece pistas muy claras sobre lo que estamos viendo. Como el autor describe, Sputtering, o pulverización catódica, es el proceso físico que provoca el parpadeo de una luz fluorescente. Explica con estas palabras en el texto que acompaña al proyecto que se trata de un efecto invisible para el ojo humano, debido a su frecuencia retiniana, pero explorable a través de una cámara fotográfica configurada con los parámetros adecuados para ello. De esta forma, el autor explica su proceso de trabajo. A través de la fórmula de la frecuencia $(\mathrm{f}=1 / \mathrm{T})$, y conociendo que los fluorescentes funcionan con una frecuencia alterna de $50 \mathrm{~Hz}$ emplea la velocidad de obturación para observar el parpadeo que estas luminarias desprenden y ver cómo se incrementa ese flickering según avanza la serie, envolviendo al espectador en una atmósfera situada en el límite de la representación, en el que puede experimentar su propia capacidad cognitiva frente a los resultados obtenidos a través de la cámara fotográfica desarrollados formalmente en una secuencia de imágenes. El autor confiesa que, mediante la secuencia de imágenes, busca mostrar la capacidad de una cámara frente a las limitaciones de la vista, y cómo la fotografía es capaz de percibir ese parpadeo o flickering a diferencia del ojo humano que, debido a la persistencia retiniana, es incapaz de percibirla.
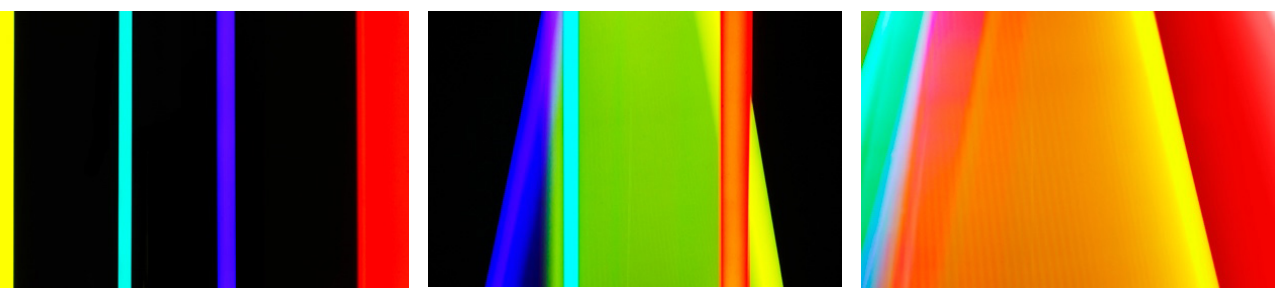

Tres fotografías de Sputtering

[Fuente: página web del artista]

Las imágenes de Isla obedecen a uno de los principios que marca el desarrollo de la fotografía en el siglo XIX: nos permite ver más. La fotografía acompaña la transformación industrial y se convierte en la herramienta que permite ampliar nuestra capacidad de ver y descubrir la nueva realidad física del mundo - las ciudades, los ferrocarriles, la máquina de vapor- que nuestro ojo es incapaz de percibir. Como ocurriera con el mítico Caballo en movimiento (1878) de Muybridge, en el trabajo de Isla las bandas de colores nos fascinan y sorprenden a partes iguales: 
cómo es posible que esos colores sean invisibles a nuestra mirada. En el siglo XIX se utilizó la fotografía para expandir la mirada hacia los confines del mundo desde lo macro, mostrando los paisajes lejanos y exóticos, pero también desde lo micro, con los estudios de movimiento y anatomía humana y animal de Eadweard $\mathrm{Mu}-$ ybridge, Etienne Jules Marey o Thomas Eakins. Con este trabajo, Isla demuestra que la cámara puede seguir operando bajo el mismo principio: la luz es redescubierta para revelar un paisaje de luces de colores que nuestra mirada no alcanza a ver. Las imágenes de Isla se construyen entonces como fotografías-máquina, a partir de un proceso técnico en el cual el fotógrafo parece no intervenir, que captura, registra, fija esa luz solo visible para la máquina, convirtiéndose en un documento de esa presencia. Es el principio de la llamada fotografía científica, que busca la cualidad de registro de la imagen, la huella, el índice, para aproximarnos lo que no podemos ver, como lo hacen los rayos X o el telescopio Hubble (en principio) sin más pretensiones poéticas o narrativas.

Sin embargo, los registros de Isla no operan aislados. Están mediados por un proceso de edición, en el que tanto el libro como el audiovisual en el que toman forma sí nos ofrecen una mirada poética. El libro - una publicación de la exposición Lanzadera en el Centro Cibeles de Madrid- busca generar una secuencia en la que atrapa in crescendo un universo presente, pero invisible. Desde el negro intenso de la portada y las primeras páginas, nos va introduciendo en un mundo de rayas de color, que se van intensificando. El color aparece por primera vez como una raya roja en el extremo derecho de una de las páginas y, a partir de ahí, va apoderándose de la página hasta convertirse en una explosión de colores y formas. El libro está compuesto por acetatos y páginas couché, que presentan al lector varias capas de aproximación. Los acetatos, siempre colocados antes de las páginas couché, añaden una capa de lectura al color, desenfocándola, ofreciendo una segunda mirada que distorsiona y desenfoca el rayo de color sobre el negro intenso de la página. El proyecto, además de existir en formato libro, ha sido trasladado a un audiovisual en el que las luces invaden la oscuridad de un campo vacío a golpes rítmicos, compuestos también por el propio Isla. Una advertencia pone en guardia al espectador: el vídeo puede producir ataques epilépticos, y es que los destellos de color actúan como flashes hasta invadir la pantalla por completo en un clímax que desafía la persistencia retiniana del ojo humano, incapaz de distinguir los planos. El proyecto ha sido adaptado a formatos expositivos, en los que, de nuevo, prima la sensación envolvente del color y destaca como una instalación de luz, donde los colores destellan en pantallas de gran formato, como se pudo ver en ETOPIA, Centro de Arte y Tecnología de Zaragoza.

La edición de las fotografías en una suerte de relato poético lleva el peso de los registros como meros documentos de la actividad lumínica a la expresión estética. Las formas y los colores -que remiten a la abstracción geométrica- nos plantean una reflexión metadiscursiva donde el motivo fotografiado, la propia luz, es también el elemento principal de registro y expresión, convirtiendo el dispositivo fotográfico en una suerte de ojo ciborg capaz de percibir una realidad alternativa a la del ojo humano. Sputtering nos habla así de dos realidades paralelas, la visible y la invisible. Las fotografías hacen visible aquello de la luz que no es visible, pero en este ejercicio señalan también que al visibilizar este proceso ocultan lo que normalmente esta luz sí nos permite ver: ¿cuál es la realidad visible que en estas imágenes no llegamos a ver? 


\subsection{El sol inscrito en el paisaje. Sol (Ricardo Cases, 2011)}

Sol es la mirada de Ricardo Cases sobre su tierra, su entorno más cercano, aquél que conoce en profundidad y habita de forma cotidiana. Y su concepción de esta tierra está marcada por un sol brillante y deslumbrante que lo invade todo con una intensidad tal que molesta a la mirada. El sol de levante no es solo una luz que se refleja en la superficie de los objetos, sino que los transforma. Los objetos, las personas y los paisajes absorben esta luz y son modelados por ella. Como afirma Luis López Navarro en la propia introducción del libro, Cases se aproxima a los estereotipos de la costa levantina siguiendo el hilo temático de su proyecto anterior El porqué de las naranjas (2014) para juguetear como un niño en busca de la representación del propio sol en sus fotografías mientras retrata la esencia de este territorio y cuestiona cómo el sol determina la identidad, la estética y la economía local, en definitiva, la cultura de un territorio.

El autor mismo reconoce cómo el sol ha marcado, casi sin darse cuenta, su vida y propone un acercamiento indirecto y respetuoso a la estrella solar:

Nací en un planeta inhóspito y rocoso, dominado por una estrella demasiado cercana. En mi cielo rota una bola de fuego inmensa que no me atrevo a mirar directamente. Me he acostumbrado a vivir con su aliento abrasador en el cogote, humillando la cabeza. La única forma de contemplarla sin riesgo es buscar discretamente su sombra en superficies, su reflejo en pozos o espejos. Con la técnica adecuada, y conociendo las distancias del cosmos, uno puede aprender a orientarse triangulando con respeto, con temor (Cases, 2017).

Un universo de colores saturados y formas geométricas nos introduce en el levante español. Sin ánimo de llegar a la abstracción, como hace Jorge Isla en Sputtering, ni siquiera de deformar lo visible como hace Barón en C.E.N.S.U.R.A., Cases nos retrata el mundo en el que habita a partir de una mirada que privilegia formas y colores y en la que nos cuesta encontrar los referentes figurativos. El autor, busca el sol en las superficies, en los reflejos, en la arquitectura o en los agujeros. Y, aunque parezca contradictorio, lo encuentra gracias a su constante uso del flash. Cases recrea ese "aliento abrasador en el cogote" lanzando fogonazos que se inscriben en el campo visual. Este rasgo, que ha sido una constante a lo largo de su obra, genera un alto contraste y una gran intensidad de color en su trabajo (Rubio (ed.), 2014). Además, una ligera sobreexposición de sus imágenes contribuye a representar la luz de la costa mediterránea que intenta retratar, demasiado intensa por lo general para poder mirar sin entornar los ojos.

Su mundo lo habitan elementos que encuentra en el propio territorio y a los que se aproxima buscando el encuadre que le permita aislarlo y transformarlo en un icono del paisaje: un flotador, unas boyas, una pared, un contendedor, un coche, una maqueta de la propia playa... son elementos comunes que se encuentran en el entorno, pero bajo la mirada de Cases devienen en símbolos de una forma de vida. No abundan los retratos, pero los que hay nos estremecen. El sujeto, que aparece en un encuadre cerrado, casi aislado del paisaje, se convierte en el propio paisaje. Son retratos de personas mimetizadas con el entorno, cuya piel ha mutado por la acción del sol, tornándose de un rojo oscuro y brillante. Rostros animados por los complementos playeros, empleados para la protección, precisamente, del sol. Gafas oscuras, ropa 
ligera, cinta para el pelo, pieles quemadas. El sol se hace patente en estos cuerpos, víctimas de su incansable energía.

El proyecto toma forma en formato libro que, a través de sus páginas satinadas, potencia la intensidad del brillo y la luz. Propone además un pequeño reto al lector, ya que contiene una serie de páginas desplegables, de forma que para ver las imágenes debemos abrirlas. Un esfuerzo extra que demanda pero que, de algún modo, fuerza a no pasar las páginas rápido, a tomarse su tiempo para descubrir y leer, con cierto detenimiento, cada una de las imágenes: se trata de recorrer el espacio de las páginas y sus rincones, sus pliegues. Además del libro, el proyecto ha sido trasladado al formato expositivo en el que se ha optado por disposiciones distintas: en una, las imágenes se suceden en la pared formando una curva que recuerda a la curva que dibuja el sol por el movimiento terrestre, desde el amanecer al anochecer. En otra, para la exposición Estudio elemental del Levante, que recogía a través de cinco series fotográficas su trabajo desde 2010 en el marco de PHotoESPAÑA 2018 en la Sala Canal de Isabel II en Madrid, se optó por colocar las imágenes en una composición que dibuja una forma ovalada que recuerda a la del sol del amanecer mediterráneo, con inclinaciones en algunas de las imágenes para atrapar -y escupir- mejor la luz de unos focos que apuntaban directamente.
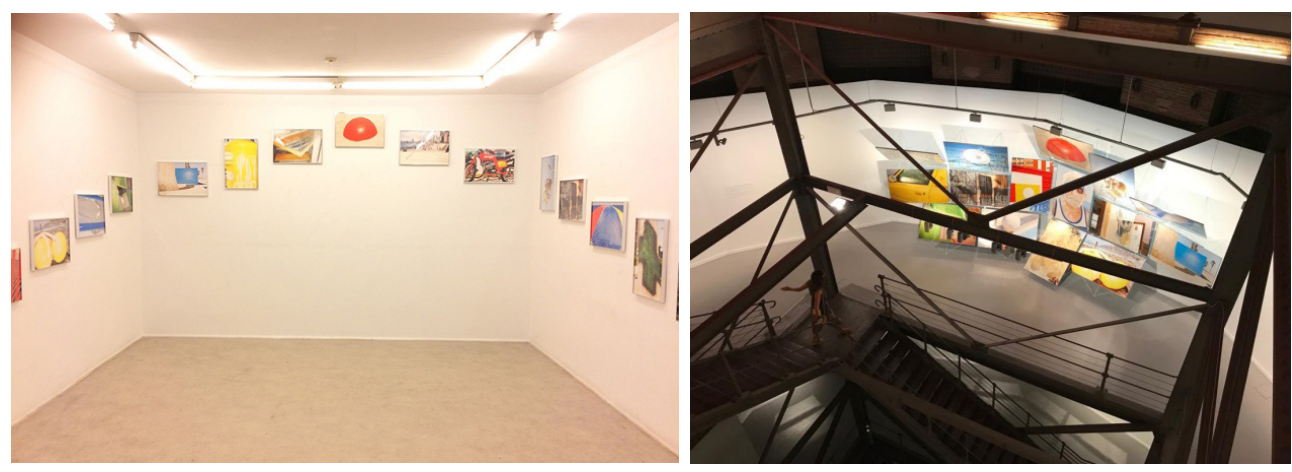

Dos disposiciones expositivas diferentes de Sol, ambas simulando el recorrido o la forma del sol. [Fuente: catálogo online de las exposiciones]

Pese a que Ricardo Cases no suele exponerse en redes sociales habitualmente, recibió la propuesta de The New Yorker de tomar su cuenta de Instagram -thenewyorkerphoto-, con casi medio millón de seguidores, para secuestrarla durante un tiempo limitado mientras editaba este proyecto. Pese a que las imágenes de Cases no son de lectura fácil, y los códigos que rigen las redes sociales son otros, el autor inundó de sol mediterráneo el timeline de esta prestigiosa revista neoyorkina. 


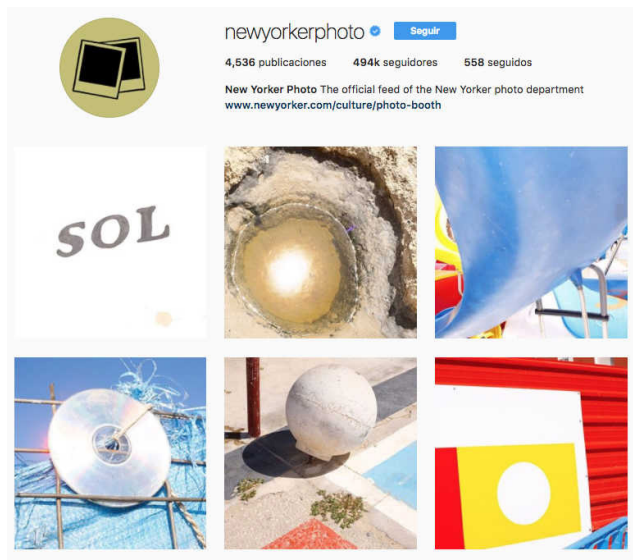

El proyecto Sol en la cuenta de Instagram de The Newyorker

[Fuente: captura de pantalla]

Sol se inscribe en lógica de la fotografía documento: parte de una realidad observable que el fotógrafo capta con su cámara, en la estela de la fotografía llamada de "estilo documental" (Lugon, 2010) pero, al contrario que Sputtering, donde esta acción de documentar se relaciona directamente con el registro científico de la imagen, aquí advertimos de forma contundente el gesto de la mirada autoral sobre el paisaje. Como indica Rouillé, "la fotografía, incluso la documental, no representa automáticamente lo real y no toma el lugar de una cosa exterior" (2014: 27). Ya Minor White, en su escrito de referencia, The camera mind and the eye, hacía referencia a que el fotógrafo se encuentra unos motivos -bien por azar o por propia disposición- que son premisas y contienen un diálogo visual previo. El fotógrafo, frente a ellos, los despoja de los contenidos previos y los integra en un argumento propio creando así una expresión, una mirada propia, previamente inexistente: "uno siente, uno ve a través del visor un mundo más allá de las superficies. El visor se vuelve como las palabras de una oración o de un poema, como dedos o cohetes adentrándose en dos infinidades: el inconsciente y el universo visual-táctil" (2004: 242). La realidad se construye así a través de la fotografía, no solo es representada o registrada, por ella.

Con Sol, Ricardo Cases aborda la luz como elemento necesario para la creación fotográfica -doblemente, del sol y del flash-, por supuesto, pero nos devuelve una mirada única de su experiencia sobre cómo transforma el territorio, cómo moldea los paisajes, los objetos comunes que encontramos en ellos, y hasta a las personas que los habitan, que se camuflan así en un espacio en el que el decoro y los códigos de comportamiento o de vestimenta habituales son sustituidos por otros propios de la playa. La luz transforma el paisaje y Ricardo Cases lo captura para expresarlo y construirlo, transformarlo desde su mirada, con todos sus matices y contradicciones, poniendo el foco en el origen mismo de la identidad de este territorio y de la propia fotografía, el sol. La lectura metadiscursiva ahonda pues en la capacidad creadora y transformadora de la luz: sobre la imagen y sobre un territorio. 


\subsection{El flash que ciega la mirada. C.E.N.S.U.R.A. (Julián Barón, 2011)}

Si en Sputtering partíamos de una fotografía-documento inscrita en la concepción más mecánica y cientifista del medio para generar una experiencia estética, y en Sol, de una imagen más próxima a la tradición documental de la fotografía, para hacer una lectura subjetiva del paisaje, entendemos C.E.N.S.U.R.A. como un proyecto donde el vínculo con esta tradición de la fotografía se lleva al extremo para cuestionarlo. En este proyecto, que ya hemos analizado en profundidad en otra publicación (Martín-Nuñez y García-Catalán, 2015) ${ }^{3}$ se hibridan procesos documentales con procesos experimentales a partir del uso de un flash completamente desbocado que quema parte de la imagen. Barón propone una mirada incómoda a la realidad política del momento reflexionando sobre la corrupción institucionalizada y la imagen del poder -y que los medios de comunicación ofrecen del poder-, reuniendo en el libro una serie de imágenes quemadas sobre papel satinado que los puristas del medio considerarían técnicamente errores. Y, efectivamente, unas fotos sobreexpuestas de carteles políticos que Barón rescató de su archivo años después de ser tomadas -y que ahora cierran el fotolibro- le permitieron ver más allá del lenguaje de la fotografía documental normativa para retratar una sociedad ciega ante la corrupción institucionalizada y saturada por el ruido mediático.

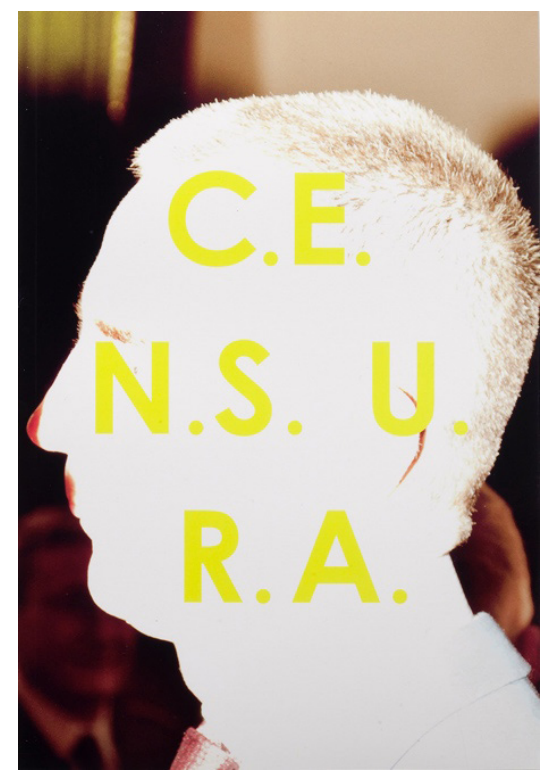

Portada del fotolibro C.E.N.S.U.R.A

[Fuente: captura de pantalla]

En este sentido, vemos aquí la huella de una tradición que, como en el caso de $\mathrm{Sol}$, se remonta a las lecturas de la realidad, pero suma también el deseo de expe-

El artículo publicado por la autora y Shaila García-Catalán en la revista Fotocinema ofrece un análisis mucho más detallado y profundo que el que presentamos aquí, donde reflejamos las conclusiones de aquél estudio y elaboramos sobre lo que allí ya se analiza. 
rimentar con la imagen y sus cualidades físicas, huyendo de las convenciones más normativas. Proyectos como American Night (2002) de Paul Graham, que experimenta con la imagen al seguir un camino creativo que parte del error accidental, laten en el trabajo de Barón. En este sentido, en estos proyectos resuenan las palabras de Mogoly-Nagy sobre el error en la fotografía:

El enemigo de la fotografía es lo convencional, las reglas rígidas de los manuales. La salvación de la fotografía está en la experimentación. El que experimenta no tiene una idea preconcebida de la fotografía. No cree que la foto, como se piensa hoy, sea la repetición y la transcripción exacta de un punto de vista ordinario. No cree que los errores fotográficos deban ser evitados, pues solo desde un punto de vista histórico convencional se les puede considerar como accidentes banales. (Moholy-Nagy, 1956: 197)

Si la fotografía nace en sus orígenes ligada a la noción de una imagen mecánica para lograr el ideal de ver más, $\mathrm{y}$, en última instancia, el flash nos permite ver y fotografiar aún más en condiciones de poca luz, aquí Barón lo subvierte porque es precisamente a partir de negar la imagen visible - borrarla de la superficie- como consigue arrojar luz a la problemática que retrata. Como hemos señalado en otro lugar, "la luz emerge como un ruido en la imagen que obstaculiza - cuando no impide- el reconocimiento de las figuras. Pero ese gesto de negación proclama cierto despertar. Emplaza, pues, una lectura ética e incomodada" (Martín-Nuñez y García-Catalán, 2015: 338).

Barón abraza el supuesto fallo, el error y la experimentación para subvertir el uso de la imagen fotográfica documento, construyendo una expresión que, en realidad, nos habla de lo real. Así, esta obra aúna la concepción lumínica de las obras analizadas antes: juega con el error y la abstracción a partir del flash radical en un juego de inversiones en la visibilidad e invisibilidad del mundo, tal y como persigue Isla, para escribir una mirada sobre una realidad social, que (d)enuncia y construye, a partir de la transformación de sus formas, tal y como hace Cases. La tensión entre su vertiente como arte y como documento se exalta, cuestionando incluso, la vigencia de estas etiquetas referidas a la fotografía.

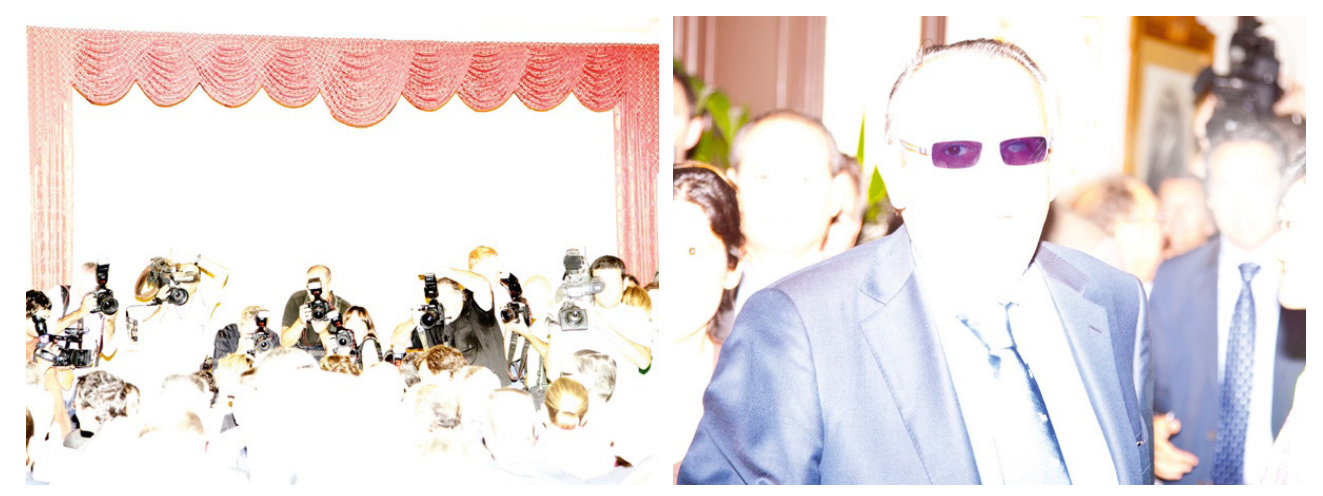

Fotografías del libro C.E.N.S.U.R A.

[Fuente: captura de pantalla] 
C.E.N.S.U.R.A, pese a estar ligado a una actualidad política determinada, ganó el Magnum Photography Award en 2016, cinco años después de su publicación en la categoría Open Series. Sus fotografías no se dejan arrastrar por el torbellino de la actualidad y, pese a que podrían ser calificadas como imágenes para tirar bajo algunos criterios, tienen una pregnancia superior a muchas de las imágenes normativas y hegemónicas que nutren los medios diariamente y cuyo consumo sí se convierte en un constante usar y tirar. Estas imágenes, no. Nos obligan a volver a ellas para preguntarnos, de nuevo, qué muestra y qué esconde la luz, en una nueva muestra metadiscursiva sobre el poder de la luz y la fotografía para reflexionar sobre sus propios discursos y silencios.

\section{Discusión y conclusiones}

Sputtering, Sol y C.E.N.S.U.R.A. nos muestran diferentes expresiones de la foto-documento. Los tres proyectos parten de la fotografía como documento, pero en cada uno toma una expresión, una escritura diferente, basada en cómo se interpreta la luz. Una luz que no es solo la posibilitadora de la imagen -su tinta, como decíamos al principio- y que también va más allá de ser un elemento expresivo. Se trata de un uso de la luz metadiscursivo con el cual los tres proyectos, a partir de la reflexión sobre la propia luz, ofrecen miradas sobre la propia capacidad de ver, de crear y de transformar mundos de la fotografía.

Sputtering es una investigación física -y fisiológica- traducida visualmente. Celebra la experiencia estética que se crea de la magia del ver y que nace al secuenciar las imágenes, creando una serie que se convierte en un viaje para los sentidos, especialmente en la secuencia audiovisual, donde se integra con el ritmo musical. Sol se encuentra con un paisaje que se reinterpreta bajo la mirada del autor, que le lanza a través del flash la intensidad lumínica que él percibe como el elemento transformador de ese territorio y de las personas que en él habitan. Y C.E.N.S.U.R.A supone una acción reivindicativa que se revuelve directamente contra la concepción de la imagen documento abrazando el error, el fallo y utilizándolo con un valor discursivo para borrar el ruido y arrojar luz a la profunda oscuridad, deformando las imágenes del poder para realizar una denuncia explícita de una realidad social. Si bien es cierto que las motivaciones, los procesos y las investigaciones detrás de estos proyectos son de naturaleza muy distinta, también lo es que los tres proyectos coloquen la luz en el centro de su discurso simbólico y formal, sirviéndose de ella como algo más que una mera posibilitadora que permite registrar la imagen.

En este recorrido, estos proyectos evidencian cierta crisis de la concepción de la fotografía-documento: los tres proyectos parten de este principio, para superarlo a través de estrategias discursivas que dan valor a la expresión y a la subjetividad de la mirada. Así, la escritura de la voz autoral queda registrada en las imágenes, que huyen de la supuesta transparencia y lecturabilidad asociada al documento para escribir una mirada sobre el mundo a partir de un uso expresivo de la luz -de las luces-. Estos proyectos ponen en valor la escritura fotográfica alejada de su función como analogía con el mundo visible, reivindicando la figura del autor y la mirada subjetiva, demostrando cómo la fotografía, más allá de limitarse a representar el mundo, lo construye. La luz establece así una relación metonímica con la fotografía: vuelve sobre sí misma para cuestionarse lo visible, lo invisible y la transformación que ejerce sobre aquello que toca. 


\section{Financiación}

El presente trabajo ha sido realizado en el marco de los proyectos de investigación $E l$ diseño narratológico en videojuegos: una propuesta de estructuras, estilos y elementos de creación narrativa de influencia postclásica (DiNaVi) (código 18I369.01/1), dirigido por Marta Martín-Núñez y Análisis de identidades discursivas en la era de la posverdad. Generación de contenidos audiovisuales para una Educomunicación crítica (AIDEP) (código 18I390.01/1) dirigido por Javier Marzal Felici. Ambos fueron financiados por la Universitat Jaume I, a través de la convocatoria competitiva de proyectos de investigación de la UJI, para el periodo 2019-2021.

\section{Uso de imágenes}

Las imágenes utilizadas como figuras en este artículo son elementos centrales del análisis, realizado únicamente con fines científicos en el ámbito académico.

\section{Bibliografía}

Barón, J. (2011). C.E.N.S.U.R.A. España: Autoeditado.

Barthes, R. (1989). La cámara lúcida. Notas sobre la fotografía. Barcelona: Paidós.

Boulouch, N. (2009). La creación experimental. In A. Gunther \& M. Poivert (Eds.), El arte de la fotografía. De los origenes a la actualidad, 459-506. Barcelona: Lungwerg.

Cases, R. (2017). Sol. Madrid: Dalpine.

Català Domenech, J. M. (2012). El murmullo de las imágenes. Imaginación, documental y silencio. Santander: Shangrila.

Chéroux, C. (2009). Breve historia del error fotográfico. México: Ediciones Vé

Clemente-Fernández, M. D., Febrer-Fernández, N., \& Martínez-Oña, M. del M. (2018). La fotografía documental como recurso en la obra de mujeres artistas: de la "flâneuse" a la cronista de realidades inventadas. Área Abierta, 18(1), 75-96. DOI: https://doi. org/10.5209/ARAB.56602

Fontcuberta, J. (1997). El beso de Judas. Fotografia y verdad. Barcelona: Gustavo Gili.

Fontcuberta, J. (2010). La cámara de Pandora. La fotografia después de la fotografia. Barcelona: Editorial Gustavo Gili.

Fontcuberta, J. (2016). La furia de las imágenes: notas sobre la postfotografia. Barcelona: Galaxia Gutemberg.

Gunther A. \& Poivert, M. (Eds.), El arte de la fotografia. De los orígenes a la actualidad. Barcelona: Lungwerg.

Isla, J. (2017). Sputtering. España: Autoeditado

Grosenick, U. (1995). The Emperor's Watch. An Interview with Paul Graham. En P. Graham. Empty Heaven. Photographs from Japan 1989-1995. Zurich, Suiza: Scalo Publishers.

Graham, P. (2003). American Night. New York: steidlMack

Langford, Michael (2008). Fotografía básica. Barcelona: Omega.

Lugon, O. (2010). El estilo documental: de August Sander a Walker Evans: 1920-1945. Salamanca: Ediciones Universidad de Salamanca.

Marzal Felici, J. (2007). Cómo se lee una fotografía. Interpretaciones de la mirada. Madrid, España: Cátedra. 
Rubio, O. M. (ed.) (2014). Diccionario de fotógrafos españoles. Del siglo XIX al XXI. Madrid, España: La Fábrica.

Martín-Núñez, M. (2009). ¿Qué es una hiperimagen?: la re-mediación de la imagen digital en la publicidad audiovisual. Valencia: Campgàfic.

Martín-Núñez, M. (2011). La cámara lúcida (y digital). La re-mediación de la fotografía en la animación infográfica. L'Atalante. Revista de Estudios Cinematográficos, 12, 48-53.

Martín-Núñez, M. y García-Catalán, S. (2015). Un segundo más y los caciques desaparecería. El flash político de Julián Barón. FOTOCINEMA. Revista científica de cine y fotografia, DOI: 10, 327-351. https://doi.org/10.24310/Fotocinema.2015.v0i10.5989

Moholy-Nagy, L. (1956). Vision in Motion. Chicago: Paul Theobald and Company.

Poivert, M. (2009). La voluntad artística. En A. Gunther \& M. Poivert (Eds.), El arte de la fotografía. De los orígenes a la actualidad, 179-228. Barcelona: Lungwerg.

Raich Muñoz, L. (2014). Poética fotográfica. Madrid: Casimiro libros.

Rouillé, A. (2017). La fotografía. Entre documento y arte contemporáneo. Ciudad de Mexico: Herder.

White, M. (2014). El ojo, la mente y la cámara. En: J. Fontcuberta (ed). Estética fotográfica. Una selección de textos. Barcelona: Gustavo Gili. 